\title{
Tissue lipid metabolism and hepatic metabolomic profiling in response to supplementation of fermented cottonseed meal in the diets of broiler chickens"
}

\author{
Cun-xi NIE, Wen-ju ZHANG ${ }^{\dagger \dagger}$, Yong-qiang WANG, Yan-feng LIU, Wen-xia GE, Jian-cheng LIU \\ (College of Animal Science and Technology, Shihezi University, Shihezi 832003, China) \\ †E-mail: zhangwj1022@sina.com
}

Received Sept. 24, 2014; Revision accepted Feb. 8, 2015; Crosschecked May 13, 2015

\begin{abstract}
This study investigated the effects of fermented cottonseed meal (FCSM) on lipid metabolites, lipid metabolism-related gene expression in liver tissues and abdominal adipose tissues, and hepatic metabolomic profiling in broiler chickens. One hundred and eighty $21-d$-old broiler chickens were randomly divided into three diet groups with six replicates of 10 birds in each group. The three diets consisted of a control diet supplemented with unfermented cottonseed meal, an experimental diet of cottonseed meal fermented by Candida tropicalis, and a second experimental diet of cottonseed meal fermented by $C$. tropicalis plus Saccharomyces cerevisae. The results showed that FCSM intake significantly decreased the levels of abdominal fat and hepatic triglycerides ( $P<0.05$ for both). Dietary FCSM supplementation down-regulated the mRNA expression of fatty acid synthase and acetyl CoA carboxylase in liver tissues and the lipoprotein lipase expression in abdominal fat tissues ( $P<0.05$ for both). FCSM intake resulted in significant metabolic changes of multiple pathways in the liver involving the tricarboxylic acid cycle, synthesis of fatty acids, and the metabolism of glycerolipid and amino acids. These findings indicated that FCSM regulated lipid metabolism by increasing or decreasing the expression of the lipid-related gene and by altering multiple endogenous metabolites. Lipid metabolism regulation is a complex process, this discovery provided new essential information about the effects of FCSM diets in broiler chickens and demonstrated the great potential of nutrimetabolomics in researching complex nutrients added to animal diets.
\end{abstract}

Key words: Fermented cottonseed meal, Lipid metabolism, Broiler, Gene expression, Metabolomics doi: 10.1631 jzus.B1400255

Document code: A

CLC number: S81

\section{Introduction}

Cottonseed meal (CSM), a major protein source used in animal feed for many years in China, has good nutritive value (Yin et al., 1993; 1994). The utilization of CSM is limited in poultry diets due to the

\footnotetext{
${ }^{\ddagger}$ Corresponding author

* Project supported by the National Natural Science Foundation of China (No. 31360564) and the Graduate Research \& Innovation Project of Xinjiang Uygur Autonomous Region of China (No. XJGRI2013059)

(D) ORCID: Cun-xi NIE, http://orcid.org/0000-0003-3320-2840; Wen-ju ZHANG, http://orcid.org/0000-0002-5314-9904

(c) Zhejiang University and Springer-Verlag Berlin Heidelberg 2015
}

presence of gossypol, a toxic polyphenol. However, to solve this problem, solid-state fermentation is an effective option (Zhang et al., 2006; 2007). Additionally, CSM by solid-state fermentation improves nutrition characteristics (Zhang et al., 2006; Sun et al., 2012; Yang et al., 2012) and produces many essential nutrients such as amino acids, small-size peptides, vitamins, and oligosaccharides (Tang et al., 2012). Yeast, a unicellular fungus, can be used as a microbial feed additive for preventing disease and encouraging growth (Koh et al., 2002). Candida tropicalis and Saccharomyces cerevisae were used in CSM fermentation by Zhang et al. (2007), who found that the two yeast strains were very effective in detoxifying 
free gossypol in CSM. In addition, CSM fermented by C. tropicalis increased the levels of total amino acids, essential amino acids, and in vitro digestible crude protein and amino acids (Zhang et al., 2007). Koh et al. (2002) reported that $S$. cerevisae and fermented rice bran resulted in various biological activities in feed additives such as strengthening the immune system and reinforcing stress-fighting capabilities. Some studies have reported that fermented CSM (FCSM) improves growth performance (Tang et al., 2012) and gut microbes (Sun et al., 2013) in broiler chickens. However, little information is known about the influence of fermented CSM on lipid metabolism in broilers.

Lipid metabolism is closely associated with the nutritional value of meat, the yield of lean meat, or efficient feed utilization (de Genova Gaya et al., 2005; Zhao et al., 2007). Furthermore, excess fat deposition results in waste for consumers or economic loss for producers. Previous studies have indicated that fermented products can decrease fat deposition and improve lipid profiles (Park et al., 2012; Cha et al., 2013). In broiler chickens, the liver is the most important organ for lipid metabolism, and lipids are primarily stored in adipose tissue (Huang et al., 2008). Fat deposition results from a complex interactive process that involves genetic and environmental factors (Hausman et al., 2009; An et al., 2013). Metabolomics can comprehensively reveal the change rule and related mechanism of the biosystem affected by exogenous substances (Patti et al., 2012); thus, it is useful to understand the lipid metabolism of broilers when fermented feed is added to their diets. Metabolomics has been successfully applied to better understand the effects of organic feed on chickens (Huber et al., 2010), and has also been used to research the metabolism of adipose tissue of chickens (Ji et al., 2012).

This study investigated the effects of fermented CSM on lipid-related gene expression in tissue and liver metabolomics changes based on gas chromatography time-of-flight mass spectrometry (GC-TOF/ MS) in yellow-feathered broiler chickens. This valuable commercial broiler species has good meat quality and its production approaches three billion animals every year in China (Tang et al., 2012). The aim of this study was to understand the effects of fermented CSM intake on the lipid metabolism of broiler chicken tissue and its mechanisms.

\section{Materials and methods}

\subsection{Substrate treatment and strains}

The CSM used in this study was obtained from the Shihezi District (Xinjiang Uygur Autonomous Region of China). The substrate treatment material was performed according to the methods of Zhang et al. (2007). The strains $C$. tropicalis and $S$. cerevisae were bred and collected by the Feed Science Institute of Zhejiang University (Hangzhou, China). These two strains were maintained in yeast extract peptone dextrose medium.

\subsection{Preparation of fermented CSMs}

The treated substrate $(1000 \mathrm{~g})$ was inoculated with $80 \mathrm{ml}$ of liquid yeast inocula $\left(10^{8}\right.$ cells $\left./ \mathrm{ml}\right)$ of C. tropicalis or both strains (the ratio of $C$. tropicalis to $S$. cerevisae was 3:7). Every inoculated substrate was blended evenly, encased in a plastic container $(50 \mathrm{~cm} \times 30 \mathrm{~cm} \times 12 \mathrm{~cm})$ and incubated at $30^{\circ} \mathrm{C}$ for $48 \mathrm{~h}$ in an incubator. After fermentation, the substrate was dried at $40{ }^{\circ} \mathrm{C}$ for $48 \mathrm{~h}$ in a draught drying cabinet. The same treatment process was performed for the unfermented CSM except that the same volume of sterile culture medium was inoculated. The chemical compositions of the unfermented CSM, the CSM fermented by C. tropicalis (Ct CSM), and the CSM fermented by C. tropicalis plus $S$. cerevisae (Ct-Sc CSM) were analyzed (AOAC, 1999) on a dry matter basis as follows: dry matter, 953,946 , and $947 \mathrm{~g} / \mathrm{kg}$; crude protein, 342,376 , and $375 \mathrm{~g} / \mathrm{kg}$; ether extract, 7.1, 7.2, and $7.4 \mathrm{~g} / \mathrm{kg}$; crude ash, 53.2, 57.6, and $58.5 \mathrm{~g} / \mathrm{kg}$ in unfermented CSM, Ct CSM, and Ct-Sc CSM, respectively. The free gossypol contents, determined by a standard method (AOCS, 2009), were $126.7,44.9$, and $33.0 \mathrm{mg} / \mathrm{kg}$, respectively. The concentration of free gossypol was less than $30 \mathrm{mg} / \mathrm{kg}$ in the diet and had no effect on the broilers' health (Özdoğan et al., 2012; Tang et al., 2012).

\subsection{Broiler breeding}

The animal care and use protocol was approved by the Animal Welfare Committee of Shihezi University (Xinjiang Uygur Autonomous Region of China). A total of 300 1-d-old Chinese yellow-feathered chickens were raised in a brooder house for $14 \mathrm{~d}$ fed a commercial diet. Then, the birds were fed the control diet for $7 \mathrm{~d}$ to acclimatize the feeds because the trial 
diets were afforded in mash form. Next, the birds underwent fasting for $12 \mathrm{~h}$ and were then weighed. After that, 180 birds were chosen from the 300 total birds according to their similar weight and randomly divided into three groups, each with 60 chickens. The chickens were raised in wire-floored cages $(120 \mathrm{~cm} \times$ $80 \mathrm{~cm} \times 50 \mathrm{~cm}$ ) located in the same room. Ten chickens were kept in each cage of six cages from each group, and each cage was equipped with two nipple water bottles and one feeder. The diets of the three groups included the unfermented CSM (control group, Con), the Ct CSM (treatment group 1, Ct), and the $\mathrm{Ct}-\mathrm{Sc} \mathrm{CSM}$ (treatment group 2, Ct-Sc). The yeast levels were $2 \times 10^{6}$ colony-forming units (CFU) per $\mathrm{g}$ in the FCSM diet. Composition of the diets and nutrient levels are presented in Table 1. The birds were housed in conditions with continuous light and ad libitum access to feed and water throughout the rearing period, and the temperature was maintained at 23 to $25{ }^{\circ} \mathrm{C}$ during the ages of 21 to $42 \mathrm{~d}$.

\subsection{Sample collection}

Six birds near the average weight (1276.81 g) were randomly selected from each group, and the 18 birds were killed by cervical dislocation to sample the abdominal fat (from the gizzard to the cloaca) and livers. Abdominal fat was calculated as the percentage of abdominal fat weight relative to the total weight of the carcass. About $5 \mathrm{~g}$ abdominal fat pared from the left sides and liver tissues sampled from left lobes were collected from birds, immediately frozen in liquid nitrogen, and then stored at $-80{ }^{\circ} \mathrm{C}$ for further analysis.

\subsection{Lipid metabolite assays of the livers}

The concentrations of triglycerides (TG), total cholesterol (TC), and total protein in the livers were measured using commercial assay kits (Nanjing Jiancheng Bioengineering Institute, Nanjing, China) according to the manufacturer's instructions with a microplate reader (Thermo Labsystems MK3, Helsinki, Finland). Total protein content was used to calculate the concentrations of TG and TC.

\subsection{RNA isolation and real-time quantitative polymerase chain reaction (qPCR) analysis}

Total RNAs of the livers and abdominal fat were isolated using TRIzol reagent (Invitrogen, Carlsbad, CA, USA) according to the manufacturer's protocol. RNA concentrations were measured using a NanoDrop ND-1000 spectrophotometer (NanoDrop, Wilmington, DE, USA) and electrophoresed on a $1 \%$ $(0.01 \mathrm{~g} / \mathrm{ml})$ denaturing agarose gel to test the integrity. All RNA samples were adjusted to the same concentration. The RNA was reverse transcribed to complementary DNA (cDNA) by PrimeScript ${ }^{\mathrm{TM}}$ RT reagent kits (TaKaRa, Shiga, Japan) according to the instructions. A real-time quantitative PCR was carried out in a 7500 Real Time PCR systems (Applied Biosystems, Foster City, CA, USA) using a SYBR-Green PCR kit (Roche Diagnostics, Laval, Quebec, Canada) according to optimized PCR protocols. The PCR programme was as follows: $95{ }^{\circ} \mathrm{C}$ for $2 \mathrm{~min}$, followed by 32 cycles of $95^{\circ} \mathrm{C}$ for $30 \mathrm{~s}$, $55^{\circ} \mathrm{C}$ for $30 \mathrm{~s}, 72^{\circ} \mathrm{C}$ for $30 \mathrm{~s}$, and $72^{\circ} \mathrm{C}$ for $10 \mathrm{~min}$.

The gene primers of fatty acid synthase (FAS), lipoprotein lipase (LPL), acetyl CoA carboxylase

Table 1 Ingredient composition of experimental diets (based on air dry matter)

\begin{tabular}{|c|c|c|c|c|c|c|c|}
\hline \multirow{2}{*}{ Ingredient } & \multicolumn{3}{|c|}{ Percentage $(\%)$} & \multirow{2}{*}{ Nutrient content } & \multicolumn{3}{|c|}{ Percentage $(\%)$} \\
\hline & Con & $\mathrm{Ct}$ & $\mathrm{Ct}-\mathrm{Sc}$ & & Con & $\mathrm{Ct}$ & $\mathrm{Ct}-\mathrm{Sc}$ \\
\hline Yellow corn & 64.35 & 64.70 & 64.65 & $\mathrm{ME}(\mathrm{MJ} / \mathrm{kg})$ & $11.94^{*}$ & $11.96^{*}$ & $11.95^{3}$ \\
\hline Soybean meal & 17.15 & 16.80 & 16.85 & Crude protein & 18.70 & 18.73 & 18.75 \\
\hline Rapeseed meal & 2.00 & 2.00 & 2.00 & Calcium & 0.87 & 0.85 & 0.84 \\
\hline Ordinary CSM & 6.00 & 6.00 & 6.00 & $\mathrm{AP}$ & 0.36 & 0.34 & 0.35 \\
\hline Unfermented CSM & 6.00 & & & Met+Cys & 0.68 & 0.68 & 0.68 \\
\hline Fermented CSM & & 6.00 & 6.00 & Lys & 1.04 & 1.03 & 1.03 \\
\hline Cottonseed oil & 1.00 & 1.00 & 1.00 & & & & \\
\hline Dicalcium phosphate & 1.20 & 1.20 & 1.20 & & & & \\
\hline Limestone & 1.30 & 1.30 & 1.30 & & & & \\
\hline Premix & 1.00 & 1.00 & 1.00 & & & & \\
\hline
\end{tabular}

CSM: cottonseed meal; ME: metabolizable energy; AP: available phosphorus; Met: methionine; Cys: cysteine; Lys: lysine; Con: control group with unfermented cottonseed meal; $\mathrm{Ct}$ : treatment group with cottonseed meal fermented by C. tropicalis; Ct-Sc: treatment group with cottonseed meal fermented by C. tropicalis plus S. cerevisiae. Premix (per kg of diet): L-lysine $\cdot \mathrm{HCl} 2 \mathrm{~g}$, DL-methionine $1.1 \mathrm{~g}$, NaCl $3 \mathrm{~g}$, choline chloride (50\%) $1 \mathrm{~g}$, Cu $6 \mathrm{mg}$, Fe $100 \mathrm{mg}$, Mn $150 \mathrm{mg}$, Zn $100 \mathrm{mg}$, Se $0.3 \mathrm{mg}$, I $0.4 \mathrm{mg}$, vitamin A 12500 IU, vitamin D $4000 \mathrm{IU}$, vitamin E $18 \mathrm{IU}$, menadione $3.0 \mathrm{mg}$, thiamin $2.0 \mathrm{mg}$, riboflavin $7.5 \mathrm{mg}$, pyridoxine $4.5 \mathrm{mg}$, vitamin $\mathrm{B}_{12} 0.02 \mathrm{mg}$, pantothenic acid $12 \mathrm{mg}$, niacin $50 \mathrm{mg}$, folic acid $1.2 \mathrm{mg}$, biotin $0.15 \mathrm{mg}$. Nutrient contents are calculated values except for crude protein and calcium. ${ }^{*} \mathrm{Data}$ for $\mathrm{ME}$ are in $\mathrm{MJ} / \mathrm{kg}$ 
(ACC), peroxisome proliferator-activated receptor $\alpha$ (PPAR- $\alpha$ ), peroxisome proliferator-activated receptor $\gamma(\mathrm{PPAR}-\gamma)$, and $\beta$-actin were designed as described by $\mathrm{Wu}(2012)$, and liver fatty acid-binding protein (L-FABP) was designed as the chicken sequences from GenBank. The sequences of the primers were follows: FAS forward, 5'-TCAGGGTGTTCTGGAA TGCAA-3', reverse, 5'-AATCCTGGTGGGCAATC GTAG-3'; LPL forward, 5'-AGTCAGAGTGAAGTC AGGCGAAAC-3', reverse, 5'-CTGCTCCAGGCA CTTCACAAATA-3'; ACC forward, 5'-CTGATGG TCTTTGCCAACTGGA-3', reverse, 5'-CACGATGT AGGCACCAAACTTGA-3'; PPAR- $\alpha$ forward, 5'-TG CACTGGAACTGGATGATAGTGA-3', reverse, 5'-T CCTACATTTACAAGACCAGGACGA-3'; PPAR- $\gamma$ forward, 5'-TGTGAAGTTCAACGCACTGGAATT A-3', reverse, 5'-GGAGCTCCAAAGCTTGCAACA-3'; L-FABP forward, 5'-ATGAGCTTCACTGGAAAGT ACGAG-3', reverse, 5'-TCTTGATGTCCTTACCCT TCTGG-3'; $\beta$-actin forward, 5'-ATTGTCCACCGCA AATGCTTC-3', reverse, 5'-AAATAAAGCCATGC CAATCTCGTC-3'. All samples were analyzed in triplicate and results were expressed as $2^{-\Delta \Delta C_{\mathrm{T}}}$ according to a previous method (Livak and Schmittgen, 2001).

\subsection{Liver metabolomics profiling analysis}

The samples of liver tissues $(100 \mathrm{mg})$ were weighed in 2-ml tubes. Chilled extraction liquid (400 $\mu$ l, the volume ratio of methanol to chloroform was $3: 1)$ at $-80{ }^{\circ} \mathrm{C}$ and internal standard $\mathrm{L}-2$ chlorophenylalanine ( $50 \mu \mathrm{l}, 0.1 \mathrm{mg} / \mathrm{ml})$ were added to each tube and homogenized in a ball mill for $5 \mathrm{~min}$ at $70 \mathrm{~Hz}$. Then, the mixture was centrifuged at $12000 \mathrm{~g}$ for $15 \mathrm{~min}$ at $4{ }^{\circ} \mathrm{C}$ and $0.35 \mathrm{ml}$ of supernatant was transferred into a fresh 2-ml GC vial, followed by evaporation to dryness under vacuum in a speedvac concentrator (Thermo Fisher Scientific, Asheville, USA). Methoxyamine $(80 \mu \mathrm{l})$ in pyridine $(20 \mathrm{mg} / \mathrm{ml})$ was added to the dried residue and vigorously vortexmixed for $2 \mathrm{~min}$. Methoximation reaction was performed at $37^{\circ} \mathrm{C}$ for $2 \mathrm{~h}$, followed by trimethylsilylation for $1 \mathrm{~h}$ by adding $100 \mu \mathrm{l}$ of bis(trimethylsilyl) trifluoroacetamide (BSTFA) with $1 \%$ trimethylchlorosilane as catalyst. At last, the solution was shaken for $1 \mathrm{~h}$ at $70{ }^{\circ} \mathrm{C}$ and cooled to room temperature.

Each sample $(1 \mu \mathrm{l})$ was injected into an Agilent $7890 \mathrm{GC}$ with an Agilent 7683 Series autosampler (Agilent, Atlanta, GA, USA). Mass spectra were detected and obtained by using Pegasus HT TOF/MS (LECO Corporation, St. Joseph, MI, USA). Helium served as the carrier gas through the column. The optimized GC/MS operating conditions were as follows: the front inlet purge flow was $3 \mathrm{ml} / \mathrm{min}$, and the gas flow rate through the column was $1 \mathrm{ml} / \mathrm{min}$. The initial temperature was kept at $80^{\circ} \mathrm{C}$ for $0.2 \mathrm{~min}$, increased to $180^{\circ} \mathrm{C}$ at a rate of $10^{\circ} \mathrm{C} / \mathrm{min}$, then increased to $240{ }^{\circ} \mathrm{C}$ at a rate of $5{ }^{\circ} \mathrm{C} / \mathrm{min}$ and finally increased to $280^{\circ} \mathrm{C}$ at a rate of $20^{\circ} \mathrm{C} / \mathrm{min}$ for $18.8 \mathrm{~min}$. The injection, transfer line, and ion source temperatures were 280,270 , and $220{ }^{\circ} \mathrm{C}$, respectively. The MS data were acquired in full scan mode over the range between 35 and $600 \mathrm{~m} / \mathrm{z}$ at a rate of $100 \mathrm{spectra} / \mathrm{s}$.

\subsection{Data collection and processing}

ChromaTOF 4.3X software (LECO, St. Joseph, MI, USA) and Leco-Fiehn Rtx 5 database were used for raw peaks extracting, the data baselines filtering and calibration of the baseline, peak alignment, deconvolution analysis, peak identification, and integration of the peak area (Kind et al., 2009). In addition, an internal standard normalization method was employed in the data analysis. The normalized peak area was fed to SIMCA-P 11.5 software (Umetrics, $\mathrm{AB}$, Sweden) for the orthogonal partial least squares-discriminant analysis (OPLS-DA). Both the variable importance in the projection (VIP) values (VIP $>1)$ obtained from the OPLS-DA and the Student's $t$-test $(P<0.05)$ were employed to find differentially expressed metabolites between the two comparison groups. The LECO/Fiehn Metabolomics Library for GC/MS metabolome date (similarity value of $70 \%$ ) was used for discriminating compound annotation.

One-way analysis of variance was performed for the data of body weight, lipid content, and gene expression via statistical software SPSS 16.0 (SPSS Inc., Chicago, IL, USA). Differences among means were tested using Duncan's multiple range tests. A significance level of 0.05 was used.

\section{Results}

\subsection{Effects of FCSM on body weight and lipid metabolite contents}

All the broiler chickens remained healthy in appearance throughout the experimental period of the 
Table 2 Effects of FCSM on body weight and lipid contents of broiler chickens

\begin{tabular}{lccccc}
\hline Group & $\begin{array}{c}\text { Initial body weight } \\
(\mathrm{g})\end{array}$ & $\begin{array}{c}\text { Final body weight } \\
(\mathrm{g})\end{array}$ & $\begin{array}{c}\text { Abdominal fat } \\
(\%)\end{array}$ & $\begin{array}{c}\text { Triglycerides } \\
(\mathrm{mmol} / \mathrm{g} \text { protein })\end{array}$ & $\begin{array}{c}\text { Total cholesterol } \\
(\mathrm{mmol} / \mathrm{g} \text { protein })\end{array}$ \\
\hline Con & $540.23 \pm 16.26$ & $1280.00 \pm 26.71$ & $2.48 \pm 0.11^{\mathrm{a}}$ & $0.85 \pm 0.09^{\mathrm{a}}$ & $0.57 \pm 0.13$ \\
$\mathrm{Ct}$ & $532.03 \pm 14.29$ & $1273.98 \pm 22.51$ & $2.01 \pm 0.26^{\mathrm{b}}$ & $0.56 \pm 0.09^{\mathrm{b}}$ & $0.50 \pm 0.08$ \\
$\mathrm{Ct}-\mathrm{Sc}$ & $535.94 \pm 18.66$ & $1276.45 \pm 28.48$ & $2.03 \pm 0.39^{\mathrm{b}}$ & $0.69 \pm 0.14^{\mathrm{b}}$ & $0.59 \pm 0.11$ \\
\hline
\end{tabular}

FCSM: fermented cottonseed meal; Con: control group with unfermented cottonseed meal; Ct: treatment group with cottonseed meal fermented by $C$. tropicalis; Ct-Sc: treatment group with cottonseed meal fermented by $C$. tropicalis plus $S$. cerevisiae. ${ }^{\text {a, b }}$ Means with different letters are significantly different $(P<0.05)$. Values are expressed as mean \pm standard deviation $(\mathrm{SD})(n=6)$

FCSM-supplemented diet. The contents of abdominal fat and hepatic TG were significantly lower in the treatment groups than in the control group $(P<0.05$ for both; Table 2). However, the body weights and TC concentrations in the liver tissues did not change after adding FCSM to the diet ( $P>0.05$ for both).

\subsection{Effects of FCSM on gene expression related to lipid metabolism}

Fig. 1 presents the results of gene expression. The gene expression of hepatic ACC and FAS in the treatment groups was significantly decreased compared with that in the controls $(P<0.05)$. The FCSM-supplemented diet significantly decreased the LPL mRNA level in abdominal fat tissues $(P<0.05)$. However, the expression levels of L-FABP, PPAR- $\alpha$, and LPL in liver tissue, and PPAR- $\gamma$ in abdominal fat tissues showed no significant changes among the three groups $(P>0.05$ for all).

\subsection{Effects of FCSM on metabolomics profiling in liver tissue}

FCSM intake caused metabolic changes of endogenous metabolites in the liver tissues of broiler chickens. Results indicated that FCSM supplementation significantly increased the levels of 1-monopalmitin, ethanolamine, and $O$-phosphoserine but decreased

Table 3 Different endogenous metabolites in the livers of broiler chickens after adding Ct CSM

\begin{tabular}{clccc}
\hline No. & Metabolite & Trend & $P$-value & VIP \\
\hline 1 & 1-Monopalmitin & $\uparrow$ & $<0.001$ & 3.56 \\
2 & 2-Mono-olein & $\downarrow$ & $<0.001$ & 1.25 \\
3 & Arachidonic acid & $\uparrow$ & 0.039 & 2.35 \\
4 & Citric acid & $\downarrow$ & 0.032 & 1.29 \\
5 & Ethanolamine & $\uparrow$ & 0.007 & 3.18 \\
6 & Myo-inositol & $\downarrow$ & 0.029 & 1.15 \\
7 & Glutamine & $\uparrow$ & 0.028 & 1.33 \\
8 & O-phosphoserine & $\uparrow$ & 0.002 & 2.15 \\
9 & Prostaglandin E2 & $\downarrow$ & 0.028 & 1.57 \\
\hline
\end{tabular}

Ct CSM: cottonseed meal fermented by C. tropicalis; VIP: variable importance in the projection. Up arrow ( $\uparrow)$ and down arrow ( $\downarrow$ ) indicate elevation and decrease of metabolite level after adding $\mathrm{Ct}$ CSM, respectively the levels of 2-mono-olein and myo-inositol $(P<0.05$ for all; Tables 3 and 4). The levels of arachidonic acid and glutamine were higher in the $\mathrm{Ct}$ group than in the Con group ( $P<0.05$ for both; Table 3$)$, while the levels of citric acid and prostaglandin E2 in the $\mathrm{Ct}$ group increased compared with the Con group $(P<0.05$ for both; Table 3). The Ct-Sc CSM group showed significantly elevated levels of fructose-6-phosphate and glycine, while the levels of 3-hydroxypyruvate and mannose declined $(P<0.05$ for all; Table 4$)$.

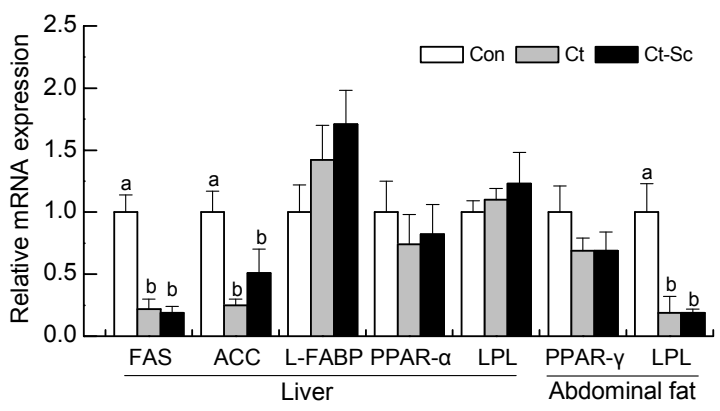

Fig. 1 Relative gene expression of mRNA in the liver tissue and abdominal fat tissue in broiler chickens fed diets containing FCSM

FCSM: fermented cottonseed meal; Con: control group with unfermented cottonseed meal; $\mathrm{Ct}$ : treatment group with cottonseed meal fermented by $C$. tropicalis; Ct-Sc: treatment group with cottonseed meal fermented by $C$. tropicalis plus $S$. cerevisiae. ${ }^{\mathrm{a}, \mathrm{b}}$ Means with different letters are significantly different $(P<0.05)$. Values are expressed as mean $\pm \mathrm{SD}(n=6)$

Table 4 Different endogenous metabolites in the livers of broiler chickens after adding Ct-Sc CSM

\begin{tabular}{clccc}
\hline No. & \multicolumn{1}{c}{ Metabolite } & Trend & $P$-value & VIP \\
\hline 1 & 1-Monopalmitin & $\uparrow$ & $<0.001$ & 2.08 \\
2 & 2-Mono-olein & $\downarrow$ & $<0.001$ & 1.73 \\
3 & 3-Hydroxypyruvate & $\downarrow$ & 0.016 & 3.26 \\
4 & Ethanolamine & $\uparrow$ & 0.018 & 1.72 \\
5 & Fructose-6-phosphate & $\uparrow$ & 0.006 & 2.73 \\
6 & Glycine & $\uparrow$ & 0.046 & 1.03 \\
7 & Mannose & $\downarrow$ & 0.020 & 2.26 \\
8 & Myo-inositol & $\downarrow$ & 0.050 & 1.01 \\
9 & $O$-phosphoserine & $\uparrow$ & 0.049 & 1.46 \\
\hline
\end{tabular}

Ct-Sc CSM: cottonseed meal fermented by $C$. tropicalis plus $S$. cerevisiae; VIP: variable importance in the projection. Up arrow $(\uparrow)$ and down arrow $(\downarrow)$ indicate elevation and decrease of metabolite level after adding $\mathrm{Ct}$-Sc CSM, respectively 


\section{Discussion}

In the present study, the CSM fermented with yeast (C. tropicalis and S. cerevisiae) decreased the abdominal fat levels of the broiler chickens, which may have been caused by the fermented products and yeast probiotics of the CSM. Similar results of decreased abdominal fat by adding fermented products and yeast in the broiler chicken diets have been reported by Yamamoto et al. (2007) and Aluwong et al. (2013), respectively. A diet containing 1.5\%-2.0\% yeast (Aluwong et al., 2013) or 1\% Koji-feed (fermented distillery by-product) (Yamamoto et al., 2007) resulted in significantly lower amounts of abdominal fat in broiler chickens.

The decreased content of abdominal fat resulted from a decrease of TG synthesis and/or enhancement of TG hydrolysis. The decreased concentrations of hepatic TG revealed that lipid synthesis was reduced when the broilers were fed the FCSM-supplemented diet, which can be associated with the reduction of abdominal fat. This notion is supported by a decrease of fatty acid synthesis because of the down-regulated mRNA expression of FAS and ACC. ACC, a rate-limiting enzyme of lipogenesis, plays a key role in the regulation of fatty acid synthesis (Numa et al., 1971). All the steps of conversion from malonyl-CoA to palmitate were catalyzed by FAS, and the FAS gene was a critical target in the control of lipogenesis (Joseph et al., 2002). The ACC and FAS have the highest correlation among lipogenic genes linked in lipogenesis (Huang et al., 2008). In addition, FCSM intake was not found to alter the lipid transport and lipid oxidation in the present study because L-FABP is involved with lipid transport, and PPAR- $\alpha$ highly expressed in the liver plays a major role in the regulation of peroxisomal $\beta$-oxidation (Lee et al., 1995). PPAR- $\gamma$ is expressed at the highest level in adipose tissue and promotes adipocyte differentiation (Mandrup and Lane, 1997), and its expression did not change after adding FCSM in the broiler chickens' diet. LPL, a critical enzyme in the hydrolysis of TG, catalyzes TG from circulating chylomicrons and very-low-density lipoprotein in adipose tissue (Zhao et al., 2013). In the present study, the down-regulated mRNA level of LPL in abdominal fat was associated with a decreased fatty acid synthesis, hepatic TG content, and fat deposition in abdominal fat in the chickens fed the diet containing FCSM. Voshol et al. (2001) reported that overexpression of muscle LPL enhances the accumulation of intramuscular TG and fat in mammals. However, FCSM supplementation did not alter the hepatic LPL expression in the broilers, which may be the result of the decreased fatty acid synthesis. A more specific reason requires further research.

Lipid metabolism is a complex process regulated by multiple metabolic pathways, such as the tricarboxylic acid (TCA) cycle, glycolysis, $\beta$-oxidation, lipogenesis, and metabolism of amino acids, which can be comprehensively revealed by metabolomics analysis (An et al., 2013; Shi et al., 2013). Metabolomics, as a systems approach, has been used to understand the lipid metabolism in the process of fat deposition in animal growth (He et al., 2012). Comprehensive analysis of metabolite changes in liver metabolic profiling was performed to reveal alterations of the lipid metabolism when broilers were on the FCSM diet in this study. The metabolites involve a variety of metabolic pathways including the TCA cycle, fatty acid synthesis, and metabolism of glycerolipids and amino acids.

The levels of citric acids were clearly lower in the $\mathrm{Ct}$ group, and the increased levels of fructose-6phosphate with decreased levels of mannose were observed in the Ct-Sc group compared wtih those in the Con group. Citric acid and fructose-6-phosphate are important intermediates which entered into the TCA cycle and gluconeogenesis to produce energy (Yang et al., 2006; Pilvi et al., 2008). Citric acid also plays an important role in biosynthesis routes, such as fatty acid biosynthesis in the liver (Liu et al., 2011). Mannose is converted into fructose-6-phosphate, which is an immediate precursor to glucose-6phosphate in gluconeogenesis, and it also further metabolizes to enter the pentose phosphate pathway. This suggested that energy metabolism was altered by adding FCSM to the birds' diets. However, differences of energy metabolism were also observed between the $\mathrm{Ct}$ and $\mathrm{Ct}-\mathrm{Sc}$ groups associated with CSM fermented by different strains. FCSM was shown to improve the intestinal bacterial microbiota (Sun et al., 2013) and further regulate energy metabolism by the gut microbiome (Donohoe et al., 2011; Velagapudi et al., 2010).

The decreased levels of 2-mono-olein and myo-inositol were accompanied by increased levels 
of ethanolamine and 1-monopalmitin in the treatment groups compared with the Con group. The 2-mono-olein and 1-monopalmitin are monoacylglycerols formed by glycerol combined with a fatty acid molecule, and these changes are believed to be associated with fatty acid synthesis or absorption. Myo-inositol and ethanolamine are the key materials needed for the synthesis of glycerol phospholipid (phosphatidylinositol or phosphatidylethanolamine). The results indicated that the FCSM-supplemented diets caused the complex metabolic effects on the lipids due to the nutritional properties of fermented CSM (Sun et al., 2012) or microbial metabolism within the host (Velagapudi et al., 2010). A previous study showed that the addition of FCSM in broiler chickens' diets increased the metabolites of glycerol phospholipids in their plasma, such as phosphatidylcholine, phophatidylethanolamine, cholesterol ester, and sphingomyelin, analyzed by metabolomics technology (Nie et al., 2013). He et al. (2012) reported that the serum of lean pigs had lower myo-inositol levels than that in obese pigs. Similarly, distinct variations of phospholipids and fatty acids were found in blood and liver tissues between obese and lean mice (Kim et al., 2011). Moreover, the idea that Ct CSM caused the up-regulation of arachidonic acid is supported by the metabolic differences. Arachidonic acid is a fatty acid combined into phospholipids of the cell membrane (Khairallah et al., 2012) or a precursor substance that forms prostaglandin $E_{2}$ (Lukivskaya et al., 2001). Arachidonic acid suppresses liver fat by influencing the gene expression or activity of lipogenic enzymes (Oikawa et al., 2009), and prostaglandin $\mathrm{E}_{2}$ protects the liver against damage from alcohol use (Lukivskaya et al., 2001).

A novel finding from this work was that amino acids (glutamine and glycine) and amino acid products (3-hydroxypyruvate and $O$-phosphoserine) were altered in the broiler chickens' livers while on the FCSM-supplemented diet. $O$-phosphoserine is a product of carbon metabolism, and it is a precursor substance that forms many amino acids, such as glycine, serine, threonine, cysteine, and methionine. The significant elevation of $O$-phosphoserine in the treatment groups showed that broilers fed the control diet needed to generate more amino acid by endogenous metabolism; that was different from the FCSM diet, which included lots of amino acid via microbial fermentation (Zhang et al., 2006; Tang et al., 2012). This was further supported by the decrease of 3-hydroxypyruvate and increase of glutamine or glycine. The 3-hydroxypyruvate can be converted to $O$-phosphoserine, which is catalyzed by phosphoserine aminotransferase. Comparison analysis of serum metabolomics indicated that obese pigs show signs of distinct metabolism of proteins and amino acids compared with lean pigs (He et al., 2012). Furthermore, it has been found that amino acid supplementation in weaned piglets' diets can alter multiple metabolite pathways associated with lipid metabolism based on serum metabolomic methods (Xiao et al., 2012).

\section{Conclusions}

This study has shown that dietary FCSM supplementation reduced the levels of abdominal fat and liver TG by down-regulating the expression of hepatic lipogenetic genes (ACC and FAS) and LPL in abdominal fat tissue. Moreover, liver metabolomics profiling analysis indicated that dietary FCSM supplementation resulted in the multiple pathway alterations in the chickens' metabolism including the TCA cycle, fatty acid synthesis, and metabolism of glycerolipid and amino acids. Thus, the regulation of lipid metabolism was found to be a complex process involving multiple pathways.

\section{Acknowledgements}

We are grateful to Dr. Jun-liang DENG (Biotree Biotechnology Co., Ltd., Shanghai, China) for providing helps in metabolomics data analysis.

\section{Compliance with ethics guidelines}

Cun-xi NIE, Wen-ju ZHANG, Yong-qiang WANG, Yan-feng LIU, Wen-xia GE, and Jian-cheng LIU declare that they have no conflict of interest.

All institutional and national guidelines for the care and use of laboratory animals were followed.

\section{References}

Aluwong, T., Hassan, F., Dzenda, T., et al., 2013. Effect of different levels of supplemental yeast on body weight, thyroid hormone metabolism and lipid profile of broiler chickens. J. Vet. Med. Sci., 75(3):291-298. [doi:10.1292/ jvms.12-0368]

An, Y., Xu, W., Li, H., et al., 2013. High-fat diet induces 
dynamic metabolic alterations in multiple biological matrices of rats. J. Proteome Res., 12(8):3755-3768. [doi:10.1021/pr400398b]

AOAC (Association of Official Analytical Chemists), 1999. Official Methods of Analysis, 16th Ed. AOAC, Washington, DC, USA.

AOCS (American Oil Chemists Society), 2009. Official Methods and Recommended Practices of the AOCS, 6th Ed. AOCS, Chicago, IL, USA.

Cha, Y.S., Kim, S.R., Yang, J.A., et al., 2013. Kochujang, fermented soybean-based red pepper paste, decreases visceral fat and improves blood lipid profiles in overweight adults. Nutr. Metab., 10(1):24. [doi:10.1186/17437075-10-24]

de Genova Gaya, L., Mourão, G.B., de Rezende, F.M., et al., 2005. Genetic trends of abdominal fat content in a male broiler chicken line. Genet. Mol. Res., 4(4):760-764.

Donohoe, D.R., Garge, N., Zhang, X., et al., 2011. The microbiome and butyrate regulate energy metabolism and autophagy in the mammalian colon. Cell Metab., 13(5): 517-526. [doi:10.1016/j.cmet.2011.02.018]

Hausman, G.J., Dodson, M.V., Ajuwon, K., et al., 2009. Board-invited review: the biology and regulation of preadipocytes and adipocytes in meat animals. J. Anim. Sci., 87(4):1218-1246. [doi:10.2527/jas.2008-1427]

He, Q., Ren, P., Kong, X., et al., 2012. Comparison of serum metabolite compositions between obese and lean growing pigs using an NMR-based metabolomic approach. J. Nutr. Biochem., 23(2):133-139. [doi:10.1016/j.jnutbio.2010.11. 007]

Huang, J., Yang, D., Gao, S., et al., 2008. Effects of soy-lecithin on lipid metabolism and hepatic expression of lipogenic genes in broiler chickens. Livest. Sci., 118(1-2):53-60. [doi:10.1016/j.livsci.2008.01.014]

Huber, M., van de Vijver, L.P.L., Parmentier, H., et al., 2010. Effects of organically and conventionally produced feed on biomarkers of health in a chicken model. Br. J. Nutr., 103(5):663-676. [doi:10.1017/S0007114509992236]

Ji, B., Ernest, B., Gooding, J.R., et al., 2012. Transcriptomic and metabolomic profiling of chicken adipose tissue in response to insulin neutralization and fasting. $B M C \mathrm{Ge}$ nomics, 13(1):441. [doi:10.1186/1471-2164-13-441]

Joseph, S.B., Laffitte, B.A., Patel, P.H., et al., 2002. Direct and indirect mechanisms for regulation of fatty acid synthase gene expression by liver X receptors. J. Biol. Chem., 277(13):11019-11025. [doi:10.1074/jbc.M111041200]

Khairallah, R.J., Kim, J., O'Shea, K.M., et al., 2012. Improved mitochondrial function with diet-induced increase in either docosahexaenoic acid or arachidonic acid in membrane phospholipids. PLOS ONE, 7(3):e34402. [doi:10. 1371/journal.pone.0034402]

Kim, H., Kim, J.H., Noh, S., et al., 2011. Metabolomic analysis of livers and serum from high-fat diet induced obese mice. J. Proteome Res., 10(2):722-731. [doi:10.1021/ pr100892r]
Kind, T., Wohlgemuth, G., Lee, D.Y., et al., 2009. FiehnLibmass spectral and retention index libraries for metabolomics based on quadrupole and time-of-flight gas chromatography/mass spectrometry. Anal. Chem., 81(24): 10038-10048. [doi:10.1021/ac9019522]

Koh, J.H., Yu, K.W., Suh, H.J., 2002. Biological activities of Saccharomyces cerevisiae and fermented rice bran as feed additives. Lett. Appl. Microbiol., 35(1):47-51. [doi:10.1046/j.1472-765X.2002.01131.x]

Lee, S.S., Pineau, T., Drago, J., et al., 1995. Targeted disruption of the alpha isoform of the peroxisome proliferatoractivated receptor gene in mice results in abolishment of the pleiotropic effects of peroxisome proliferators. Mol. Cell. Biol., 15(6):3012-3022.

Liu, G., Wang, Y., Wang, Z., et al., 2011. Nuclear magnetic resonance (NMR)-based metabolomic studies on urine and serum biochemical profiles after chronic cysteamine supplementation in rats. J. Agric. Food Chem., 59(10): 5572-5578. [doi:10.1021/jf104129k]

Livak, K.J., Schmittgen, T.D., 2001. Analysis of relative gene expression data using real-time quantitative PCR and the $2^{-\Delta \Delta C_{\mathrm{T}}}$ method. Methods, 25(4):402-408. [doi:10.1006/ meth.2001.1262]

Lukivskaya, O.Y., Maskevich, A.A., Buko, V.U., 2001. Effect of ursodeoxycholic acid on prostaglandin metabolism and microsomal membranes in alcoholic fatty liver. Alcohol, 25(2):99-105. [doi:10.1016/S0741-8329(01)00171-9]

Mandrup, S., Lane, M.D., 1997. Regulating adipogenesis. J. Biol. Chem., 272(9):5367-5370. [doi:10.1074/jbc.272.9. 5367]

Nie, C., Zhang, W., Yan, L., et al., 2013. A metabolomics study on chicken plasma based on fermented feed from cottonseed meal mixed substrate. Acta Vet. Zootech. Sin., 44(5):737-744 (in Chinese). [doi:10.11843/j.issn.03666964.2013.05.010]

Numa, S., Nakanishi, S., Hashimoto, T., et al., 1971. Role of acetyl coenzyme A carboxylase in the control of fatty acid synthesis. Vitam. Horm., 28:213-243. [doi:10.1016/S00836729(08)60895-X]

Oikawa, D., Tsuyama, S., Akimoto, Y., et al., 2009. Arachidonic acid prevents fatty liver induced by conjugated linoleic acid in mice. Br. J. Nutr., 101(10):1558-1563. [doi:10.1017/S0007114508091253]

Özdoğan, M., Wellmann, K., Paksuz, E., 2012. Effect of gossypol on blood serum parameters and small intestinal morphology of male broilers. J. Anim. Physiol. Anim. Nutr., 96(1):95-101. [doi:10.1111/j.1439-0396.2010.01126.x]

Park, J.A., Tirupathi Pichiah, P.B., Yu, J.J., et al., 2012. Antiobesity effect of kimchi fermented with Weissella koreensis OK1-6 as starter in high-fat diet-induced obese C57BL/6J mice. J. Appl. Microbiol., 113(6):1507-1516. [doi:10.1111/jam.12017]

Patti, G.J., Yanes, O., Siuzdak, G., 2012. Innovation: metabolomics: the apogee of the omics trilogy. Nat. Rev. Mol. Cell Biol., 13(4):263-269. [doi:10.1038/nrm3314]

Pilvi, T.K., Seppänen-Laakso, T., Simolin, H., et al., 2008. 
Metabolomic changes in fatty liver can be modified by dietary protein and calcium during energy restriction. Word J. Gastroenterol., 14(28):4462-4472. [doi:10.3748/ wjg. 14.4462]

Shi, X., Xiao, C., Wang, Y., et al., 2013. Gallic acid intake induces alterations to systems metabolism in rats. $J$. Proteome Res., 12(2):991-1006. [doi:10.1021/pr301041k]

Sun, H., Tang, J.W., Yao, X.H., et al., 2012. Improvement of the nutritional quality of cottonseed meal by Bacillus subtilis and the addition of papain. Int. J. Agric. Biol., 14(4):987-993.

Sun, H., Tang, J.W., Fang, C.L., et al., 2013. Molecular analysis of intestinal bacterial microbiota of broiler chickens fed diets containing fermented cottonseed meal. Poult. Sci., 92(2):392-401. [doi:10.3382/ps.2012-02533]

Tang, J.W., Sun, H., Yao, X.H., et al., 2012. Effects of replacement of soybean meal by fermented cottonseed meal on growth performance, serum biochemical parameters and immune function of yellow-feathered broilers. Asian Australas. J. Anim. Sci., 25(3):393-400. [doi:10.5713/ajas. 2011.11381]

Velagapudi, V.R., Hezaveh, R., Reigstad, C.S., et al., 2010. The gut microbiota modulates host energy and lipid metabolism in mice. J. Lipid Res., 51(5):1101-1112. [doi:10. 1194/jlr.M002774]

Voshol, P.J., Jong, M.C., Dahlmans, V.E.H., et al., 2001. In muscle-specific lipoprotein lipase-overexpressing mice, muscle triglyceride content is increased without inhibition of insulin-stimulated whole-body and musclespecific glucose uptake. Diabetes, 50(11):2585-2590. [doi:10.2337/diabetes.50.11.2585]

Wu, X.H., 2012. Effect and Regulation of Linseed Oil on Meat Quality and Fat Metabolism of Broilers. PhD Thesis, Univ. Northwest A \& F, Yangling, China (in Chinese).

Xiao, Y.P., Wu, T.X., Sun, J.M., et al., 2012. Response to dietary L-glutamine supplementation in weaned piglets: a serum metabolomic comparision and hepatic metabolic regulation analysis. J. Anim. Sci., 90(12):4421-4430. [doi:10.2527/jas.2012-5039]

Yamamoto, M., Saleh, F., Tahir, M., et al., 2007. The effect of Koji-feed (fermented distillery by-product) on the growth performance and nutrient metabolizability in broiler. $J$. Poul. Sci., 44(3):291-296. [doi:10.2141/jpsa.44.291]

Yang, L., Kasumov, T., Yu, L., et al., 2006. Metabolomic assays of the concentration and mass isotopomer distribution of gluconeogenic and citric acid cycle intermediates. Metabolomics, 2(2):85-94. [doi:10.1007/s11306006-0019-1]

Yang, X., Sun, J.Y., Guo, J.L., et al., 2012. Identification and proteomic analysis of a novel gossypol-degrading fungal strain. J. Sci. Food Agric., 92(4):943-951. [doi:10.1002/ jsfa.4675]

Yin, Y.L., Zhong, H.Y., Huang, R.L., et al., 1993. Nutritive value of feedstuffs and diets for pigs: I. chemical composition, apparent ileal and fecal digestibility. Anim. Feed Sci. Tech., 44(1-2):1-27. [doi:10.1016/0377-8401 (93)90034-H]

Yin, Y.L., Chen, C.M., Zhong, H.Y., et al., 1994. Apparent digestibility of energy, cell wall constituents, crude protein and amino acids of the Chinese oil seed meals for growing pigs. Anim. Feed Sci. Tech., 45(3):283-298. [doi:10.1016/0377-8401(94)90033-7]

Zhang, W.J., Xu, Z.R., Sun, J.Y., et al., 2006. Effect of selected fungi on the reduction of gossypol levels and nutritional value during solid substrate fermentation of cottonseed meal. J. Zhejiang Univ.-Sci. B (Biomed. \& Biotechnol.), 7(9):690-695. [doi:10.1631/jzus.2006.B0690]

Zhang, W.J., Xu, Z.R., Zhao, S.H., et al., 2007. Development of a microbial fermentation process for detoxification of gossypol in cottonseed meal. Anim. Feed Sci. Tech., 135(1-2):176-186. [doi:10.1016/j.anifeedsci.2006.06.003]

Zhao, S., Ma, H., Zou, S., et al., 2007. Effects of in ovo administration of DHEA on lipid metabolism and hepatic lipogenetic genes expression in broiler chickens during embryonic development. Lipids, 42(8):749-757. [doi:10. 1007/s11745-007-3068-y]

Zhao, X., Guo, Y., Guo, S., et al., 2013. Effects of Clostridium butyricum and Enterococcus faecium on growth performance, lipid metabolism, and cecal microbiota of broiler chickens. Appl. Microbiol. Biotechnol., 97(14):64776488. [doi:10.1007/s00253-013-4970-2]

\section{中文概要}

题 目: 肉鸡日粮中添加发酵棉粕对其组织脂类代谢及 肝脏代谢谱的影响

目 的: 旨在研究发酵棉粕对肉鸡脂类代谢的影响。

创新点: 将荧光定量聚合酶链反应 PCR 和代谢组学方法 相结合, 就采食发酵饲料 (发酵棉粕) 肉鸡的组 织脂类代谢相关基因及肝脏代谢谱进行分析, 发 现发酵棉粕具有调控肉鸡脂类代谢的作用。该研 究为研究日粮中复杂营养素对动物机体代谢的 调控提供了新思路。

方 法: 将 180 只 21 日龄肉鸡随机分为三组, 每组 6 个 重复, 每个重复 10 只鸡。对照组饲喂未发酵棉 粕底物, 试验组分别饲喂热带假丝酵母发酵棉粕 和热带假丝酵母与酿酒酵母复合发酵棉粕。饲喂 21 天后, 采集肉鸡腹部脂肪和肝脏进行组织基因 表达和肝脏代谢组学分析。

结 论: 发酵棉粕可通过下调肝脏 FAS、ACC 和腹脂 LPL 等基因的表达, 改变肝脏多种内源性代谢的代谢 途径, 进而降低肉鸡腹部脂肪沉积和肝脏甘油三 酯含量。

关键词: 发酵棉粕; 脂类代谢; 肉鸡; 基因表达; 代谢组学 